Síndrome de Guillain Barré y virus influenza. Guillain-Barré syndrome after exposure to influenza virus. Lehmann $H C$, Hartung $H P$, Kieseier $B C$, Hughes $R$ A. Lancet Infect Dis 2010; 10: 643-51.
Introducción: El virus influenza afecta anualmente a un porcentaje importante de la población. La aparición de un nuevo subtipo de influenza A H1N1 el año 2009, de origen porcino, con una rápida diseminación mundial, motivó el rápido desarrollo de vacunas y una masiva campaña de inmunización. Esto trajo al recuerdo lo ocurrido con la campaña de vacunación que se realizó el año 1976, con una vacuna con un subtipo también de origen porcino, que fue suspendida por la asociación con síndrome de Guillain Barré (SGB).

El SGB es un evento de baja frecuencia relacionado a inmunizaciones; sin embargo, estudios epidemiológicos lo han asociado a la infección por virus influenza o cuadros similares a influenza. En esta revisión se analiza la asociación de influenza o vacunas de influenza con SGB.

El SGB es una neuropatía adquirida, periférica, aguda, distinguiéndose varios subtipos desde el punto de vista electromiográfico y patogénico. El 90-95\% de los casos corresponde a una poliradiculoneuropatía desmielinizante- presentación que es más frecuente en Europa y E.U.Ase caracteriza por cambios desmielinizante secundario a una infiltración de células $\mathrm{T}$, macrófagos y daño axonal secundario. La forma axonal, en cambio, es más frecuente en Asia y América y se caracteriza por la presencia de anticuerpos dirigidos al axón. Existen otras variantes como la de Miller Fisher. La incidencia anual de SGB es de 0,4 a 4 casos/100.000. En $60 \%$ de los casos es precedido por una infección cuyo agente más frecuente es Campylobacter jejuni. La base patogénica de la enfermedad es el mimetismo molecular entre antígenos representados en un agente infeccioso y estructuras nerviosas.

SGB post vacuna influenza. La influenza pandémica de origen aviar del año 1918-20, se asoció a polineuritis post-infecciosa. Después de la pandemia esta asociación se describió en forma anecdótica y en serie de casos, en brotes por otros subtipos. Posteriormente, influenza se ha asociado en forma anecdótica a SGB y estudios recientes han demostrado una asociación causal con influenza A y B.

Un estudio realizado en París encontró evidencia serológica de influenza en 405 pacientes con SGB. La incidencia mensual de SGB con una causa no identificada fue correlacionada con el número de casos reportados similares a influenza; se encontró evidencia de influenza A en $13,7 \%$ y B en 5,5\%. Un estudio inglés investigó la relación temporal entre SGB e influenza durante los años 1990 y 2005, encontrando una incidencia relativa de 16-64 a los 0-30 días (IC 95\%: 9,37-29,54) y 7,35 a los 0-90 días (IC 95\%: 4,36-12,38), sin aumento de casos relacionado a la vacuna anti-influenza. Otro grupo que trabajó con la misma base de datos los años 1990 a 2001, encontró un aumento de SGB a los dos meses de infección asociado a cuadros similares a influenza o infección respiratoria aguda. Estos resultados son consistentes con informes semanales de influenza confirmados e ingresos semanales de SGB en Inglaterra en los años 1993-2002. Se ha reportado en forma esporádica $\mathrm{SGB}$ en casos de influenza 2009 AH1N1.

Presentación clínica y patogénesis: Los casos reportados de SGB post influenza sugieren que la presentación clínica no difiere de la de otros agentes virales, con excepción del compromiso de pares craneales descrito en una serie de casos. El período de presentación varía entre 3 y 30 días, con un promedio de 15 días.

El mimetismo molecular de agentes virales y estructuras nerviosas son escasos, lo que plantea varias interrogantes. El virus H1N1 A/NJ/1976 desarrollado en huevos de pollo tiene múltiples epítopes que son reconocidos por anticuerpos GM1. La relevancia de este hallazgo es desconocida y se ha atribuido a una retención artificial del gangliósido en la hemaglutinina viral. En un caso de SGB asociado a infección por influenza se encontró la presencia de anticuerpos anti GDlb.

Síndrome de Guillain Barré post inmunización. En el año 1976 la campaña de inmunización contra el subtipo $\mathrm{A} / \mathrm{NJ} / 1976$, fue interrumpida por la notificación de casos de SGB. Se distribuyeron 40 millones de dosis, con 532 casos de SGB reportados al CDC. La tasa de ataque fue mayor en los vacunados durante las primeras 6 semanas, en todos los grupos de edad. Se presentaron 7,2 casos (7,4 en adultos) en los vacunados vs 0,79 casos $(0,97$ en adultos) en los no vacunados. Los casos atribuidos a la vacuna fueron 8,8 casos por millón de vacunados. Estos datos fueron confirmados en estudios epidemiológicos realizados en Ohio, Michigan y Minessota.

Inmunización de influenza estacional. Con posterioridad al año 1976 se realizaron varios estudios buscando la posible asociación entre SGB y vacuna anti-influenza estacional. A pesar de las diferencias metodológicas observadas en los estudios, no se demostró riesgo o asociación significativa. Los años 1993-4, el sistema de vigilancia de eventos adversos de EUA, registró un aumento de los casos de SGB en el período anterior de circulación de influenza estacional y durante el período de estudio sólo un caso adicional por 1 millón de vacunados.

Otro estudio analizó los casos de SGB en adultos entre los años 1999 y 2003 comprobando una disminución de 0,17/100.000 vacunados en los años 1993-4 a 0,04/100.000 durante los años 2003-4, lo que fue confirmado en otro estudio con datos de influenza de los años 1990-2005. La interpretación de los datos provenientes del sistema de registro de reacciones adversas y del CDC tiene algunas limitaciones como la sub-notificación, calidad e información completa de las variables, sesgos y ausencia de controles en los no vacunados, por la atención pública que esto genera. Stowe y cols, en Inglaterra, estudiaron la asociación de SGB y vacuna en el período 1990-2005, a través de casos y controles de vacunados $v s$ no vacunados y no encontró aumento de los casos de SGB transcurridos 
90 días desde la inmunización. Otro estudio realizado en la práctica general tampoco encontró aumento de SGB a los 42 días post algún tipo de inmunización con RR de 1,02 (IC 95\%: 0,48-2,18) o post vacuna influenza estacional, RR 0,99 (IC 95\%:0,31-3,12). Un estudio realizado en Ontario, Canadá, demostró un leve aumento de la incidencia de SGB a las 2-7 semanas post inmunización, con un RR de 1,45 (IC95\%: 1,05-1,99). Sin embargo, la tasa de ingresos por SGB no aumentó después de la introducción de un programa de vacunación universal el año 2000 en la región.

Existen dudas respecto al período post inmunización en que es razonable buscar esta asociación, la mayoría se basa en 6 semanas de acuerdo a la experiencia vivida el año 1976. El período de inicio de SGB por lo general es de dos semanas, lo que sugiere una respuesta inmune primaria. La patogénesis de SGB relacionada a inmunización no es clara y podría estar asociada a una respuesta inmunológica secundaria. Esta enfermedad es monofásica, pero se ha descrito más de $60 \%$ de recaídas o recurrencias. Dos casos de SGB asociado a vacuna anti-influenza A/ $\mathrm{NJ} / 76$ presentaron recurrencia. Estudios posteriores con la vacuna anti-influenza estacional no han demostrado esta asociación. Existe evidencia epidemiológica sólida que no demuestra una asociación de la vacuna anti-influenza con SGB.

Patogénesis. Estudios epidemiológicos sugieren que la vacuna $\mathrm{A} / \mathrm{NJ} / 76$ se relaciona a los casos de $\mathrm{SGB}$, más que formulaciones específicas o lotes de vacunas. Algunos artículos han demostrado que casos de SGB o de Miller Fisher después de una inmunización a influenza, están asociados a la presencia de anticuerpos contra gangliósidos GD1b y GQ1b. En ratones las vacunas A/NJ/76 e influenza estacional de los años 1991-2 y 2004-5, fueron capaces de inducir anticuerpos anti-hemaglutinina y al gangliósido M1. Estudios cromatográficos han demostrado que la vacuna $\mathrm{A} / \mathrm{NJ} / 76$ contiene glicanos y en la vacuna 2004-5 estos glicanos pueden ser teñidos con anticuerpos GM1-similar. Nachamkim y cols han propuesto que la hemaglutinina viral que se une a carbohidratos contiene ácido siálico, el que puede formar compuestos estables de ácido siálico y hemaglutinina. Estos complejos pueden ser disueltos por la neuraminidasa viral que cataliza la hidrólisis de residuos de ácido siálico terminal y una baja actividad de esta enzima no es capaz de remover los residuos de ácido siálico, lo que resulta en una estructura que simula epítopes de gangliósidos. Se cree que esto ocurrió con la vacuna $\mathrm{A} / \mathrm{NJ} / 76$. Estudios experimentales descartaron que la vacuna hubiese sido contaminada con antígenos bacterianos.

Conclusiones. Las campañas de inmunización contra influenza 2009 AH1N1 han finalizado en varios países y hasta ahora se ha demostrado que es una vacuna segura. En varios países existe una activa campaña de seguimiento de los efectos adversos de esta vacuna, incluido SGB. Resultados preliminares en EUA muestran un leve aumento de la enfermedad, similar a lo ocurrido los años 1993-4.

La infección por influenza parece ser un gatillante relevante para SGB por lo que la vacunación puede proteger contra la enfermedad. El riesgo beneficio debe ser interpretados con cautela, porque la composición de la vacuna varía anualmente y los cambios menores del virus de la influenza estacional pueden alterar el riesgo de SGB post infección o inmunización.

\section{Lecturas recomendadas}

1.- Preliminary results: surveillance for Guillain-Barré syndrome after receipt of influenza A (H1N1) 2009 monovalent vaccine - United States, 2009-2010. MMWR Morb Mortal Wkly Rep 2010; 59: 657-61

2.- Haber P, Sejvar J, Mikaeloff Y, De Stefano F. Vaccines and Guillain-Barre syndrome. Drug Saf 2009; 32: 309-23.

3.- Evans D, Cauchemez S, Hayden FG. Prepandemic immunization for novel influenza viruses, "swine flu" vaccine, Guillain-Barre syndrome, and the detection of rare severe adverse events. J Infect Dis 2009; 200: 321-8.

Leonor Jofré $M$. Servicio de Pediatría Hospital Clínico Universidad de Chile 